\title{
Response of the Brain to Enrichment*
}

\author{
MARIAN C. DIAMOND \\ Department of Integrative Biology, 3060 Valley Life Sciences Building \\ University of California, Berkeley, CA94720, USA \\ Manuscript received on March 5, 2001; accepted for publication on March 12, 2001; \\ presented by LENY A. CAVALCANTE
}

\begin{abstract}
Before 1960, the brain was considered by scientists to be immutable, subject only to genetic control. In the early sixties, however, investigators were seriously speculating that environmental influences might be capable of altering brain structure. By 1964, two research laboratories proved that the morphology and chemistry or physiology of the brain could be experientially altered (Bennett et al. 1964, Hubel and Wiesel 1965). Since then, the capacity of the brain to respond to environmental input, specifically "enrichment," has become an accepted fact among neuroscientists, educators and others. In fact, the demonstration that environmental enrichment can modify structural components of the rat brain at any age altered prevailing presumptions about the brain's plasticity (Diamond et al. 1964, Diamond 1988).

The cerebral cortex, the area associated with higher cognitive processing, is more receptive than other parts of the brain to environmental enrichment. The message is clear: Although the brain possesses a relatively constant macrostructural organization, the ever-changing cerebral cortex, with its complex microarchitecture of unknown potential, is powerfully shaped by experiences before birth, during youth and, in fact, throughout life. It is essential to note that enrichment effects on the brain have consequences on behavior. Parents, educators, policy makers, and individuals can all benefit from such knowledge.
\end{abstract}

Key words: enrichment, cerebral cortex, hippocampus, aging, adult neurogenesis, dendrites.

\section{INTRODUCTION}

Can experience produce measurable changes in the brain? The hypothesis that changes occur in brain morphology as a result of experience is an old one. In 1815 Spurzheim asked whether organ size could be increased by exercise. He reported that the brain as well as muscles could increase with exercise "because the blood is carried in greater abundance to the parts which are excited and nutrition is performed by the blood." In 1874 Charles Darwin mentioned that the brains of domestic rabbits were consider-

\footnotetext{
*Invited paper
}

E-mail: diamond@socrates.Berkeley.EDU ably reduced in bulk in comparison with those from the wild because, as he concluded, these animals did not exert their intellect, instincts, and senses as much as did animals in the wild. However, it was not until the 1960s, that the first controlled studies in animals demonstrated that enriching the environmental condition in which they were confined could alter both the chemistry and anatomy of the cerebral cortex and, in turn, improve the animals' memory and learning ability.

In these early experiments only the brains of young animals were studied. Although many were impressed to learn that the cerebral cortex could in- 
crease its thickness in response to enriched living conditions, they raised the question about whether enrichment might similarly affect older animals. Once middle-aged rats brains showed positive responses to enrichment, the next step was to experiment with very old animals. Once again, increases in cortical thickness were found. It then became important to discover what was responsible for these changes.

One step at a time, the level of morphological changes - from neuronal soma size, to number and length of dendrites, to types and numbers of dendritic spines, to synaptic thickening, to capillary diameter, and to glial types and numbers - was examined. Age, gender, duration of exposure, etc. were critical variables that had to be tested in new experiments.

Most of the basic data reported on the enrichment paradigm and its impact on brain and behavior have accumulated through studies on the rat. Effects of enriched and impoverished environments on the nerve cells and their neurotransmitters in the cerebral cortex have now been generalized to several mammalian and avian species (Rosenzweig and Bennett 1996). Some corroborating studies mentioned herein involved cats and monkeys, as well as isolated studies in human subjects. For example, Jacobs et al. (1993) using an isolated portion of the human cerebral cortex responsible for word understanding, Wernicke's area, compared the effects of enrichment in tissue from deceased individuals who had had a college education and from those who had had only a high school education. They demonstrated that the nerve cells in the college-educated showed more dendrites than those in the latter. (Tissue was obtained from the Veteran's Hospital in west Los Angeles.) Experiments on human tissue frequently support the data obtained from studies in the rat, and, in turn, benefit from these animal studies. We can now safely say that the basic concept of brain changes in response to enrichment hold true for a wide variety of animals and for humans.

\section{THE EFFECTS OF ENRICHMENT ON THE CEREBRAL CORTEX}

What do we mean by "enrichment" for the rats who have served as the animal of choice for most of these studies? Thirty six Long-Evans rats were sorted into three experimental conditions using 12 animals in each group: 1) enriched 2) standard or 3) impoverished environments. All animals had free access to food and water and similar lighting conditions. Eventually, it was determined that animals maintained in their respective environments from the age of 30 days to 60 days developed the most extensive cerebral cortical changes. For the enriched environment, the 12 animals lived together in a large cage $(70 \times 70 \times 46 \mathrm{~cm})$ and were provided $5-6$ objects to explore and climb upon (e.g., wheels, ladders, small mazes). The objects were changed two to three times a week to provide newness and challenge; the frequent replacement of objects is an essential component of the enriched condition. The combination of "friends" and "toys" was established early on by Krech as vital to qualify the experiential environment as "enriched." (Krech et al. 1960). For the standard environment, the animals were housed 3 to a small cage $(20 \times 20 \times 32 \mathrm{~cm})$ with no exploratory objects. For the impoverished environment, one animal remained alone in a small cage with no exploratory objects.

The numbers of animals placed in these separate conditions were based on the manner in which the routine housing was established in the rat colony. Three rats in a cage has been considered standard for all experimental work over the decades. Since prior to these experiments no one had designed studies to examine brain changes in response to different environmental conditions, the decisions about what represented "impoverishment" and what represented "enrichment" was more arbitrarily than scientifically reasoned.

After 30 days in their respective environments, all animals were anesthetized before the brains were removed for comparison among the three groups. Twenty micrometer frozen sections were cut and 
stained, and the thickness of the frontal, parietal and occipital cortices were measured. Results indicated clearly that the cortex from the enriched group had increased in thickness compared with that living in standard conditions, whereas, the brains from the impoverished group decreased compared to the standard. Because the nerve cells were farther apart in the enriched vs. the impoverished brains, it was thought that the major component of the brain changes due to enrichment had to do with alterations in the dendritic branching. With more detailed studies, the cortical thickness increases were found to be due to several factors, including increased nerve cell size, number and length of dendrites, dendritic spines, and length of postsynaptic thickening as measured on electron microscopic pictures of synapses. (Diamond et al. 1964 and 1988).

In the initial experiments designed to explore the impact of an enriched environment on the brain of post-weaned rats, only enriched and impoverished groups were used. Rats were maintained in their respective environments from 25 to 105 days of age because there were no available data on how long it would take to create chemical or structural changes in the cortex. Chemical and anatomical measurements taken from these animals showed significant differences between the two groups - in cortical thickness, cortical weight, acetylcholinesterase, cholinesterase, protein and hexokinase levels, (Bennett et al. 1964, Diamond et al. 1964). In these initial experiments, however, it was not clear if the changes were due to enrichment or impoverishment because there were no standard conditions established as controls.

Nonetheless, the differences in cortical thickness with this 80-day exposure to the two environmental conditions were not as great as during the 30-day exposure. Consequently, in subsequent experiments, the period of exposure to the experimental conditions was reduced from 80 days to 30 days, then 15 days, 7 days and finally to 4 days. At each of these intervals, animals from the enriched environment showed increases in cerebral cortical thick- ness in some areas but not in others. For example, in the male animals exposed for 80 days to enriched conditions, the somatosensory cortex did not show significant changes, whereas male animals exposed for 30 days did develop significant differences in the somatosensory cortex. The occipital cortex showed significant changes for both the 80- and the 30-day experiments, but, again, the differences were greater at 30 days than at 80 days. It is possible that the longer exposure served to increase cortical thickness in the early days of enrichment but that over time the environmental condition became monotonous and this effect decreased. In later experiments the experimental conditions were modified to try to establish what the major factors were that created the observed cortical changes. For example, was the effect associated with the number of rats exposed or to the presence of stimulus objects?

The new conditions included one rat living alone in the large enrichment cage with the objects that were changed several times each week. The cortex of these rats did not show a significant effect of enrichment. Twelve rats living together in the large cage without the stimulus objects did not show as great an effect as 12 rats living with the stimulus objects. In other words, the combination of social conditions and frequent exposure to new stimulus objects were necessary for the animals to gain the full effect of enrichment.

Establishing what constitutes "enrichment" for human beings is more problematic. Not only are controlled experiments not feasible, but no two human brains are identical. Individuals differ in their genetic backgrounds and environmental inputs. Furthermore, what is considered enrichment for one individual may be quite different for another. Yet, as mentioned earlier, the enrichment effect was evident in Wernicke's area from measurements of the amount of dendritic branching in brain tissue from college-educated individuals versus that from high school-educated people. The basic finding of dendritic growth in response to environmental stimulation appears in all brains studied to date. It would 
appear that newness and challenge are important for the human cortex as well as for that of animals.

\section{IndePendent Variables: Age ANd Gender}

Among the many variables researchers must consider as they seek to understand and accurately interpret the effects of enrichment on the brain, age and gender are important considerations. Enrichment has been shown to enhance many aspects of cortical structure at any age - from prenatal to extremely old rats (904 days of age). The amount of change varies with the age of the animal. For example, when a 30-day-old rat is put in an enriched environment for four days, the effects are not as pronounced as they are in the 60-day-old-rat maintained in enriched conditions for four days. Is four days too short a time for the very young animal to adjust and benefit from enrichment? A young animal maintained for 30 days in an impoverished environment shows reduced morphological development of its cortex when compared to that of an adult animal maintained in impoverished conditions for 30 days. In further age-related experiments, another component was added to the enrichment conditions of old rats. Despite significant increases in the length of the dendrites in the brains of 600-day-old rats that had been placed in an enriched environment for 30 days (600 to 630 days), several of the old rats in this population died.

To determine whether the enrichment conditions could be modified to extend the animals' life span, the investigators added a new component: hand-holding the rats each day for several minutes while the cages were cleaned. In an attempt to increase the life span of the rats, rats were placed three to a cage after weaning at 25 days of age, and maintained in these standard conditions until they reached 766 days, at which time half went into enriched conditions until they reached 904 days of age and half stayed in the standard conditions. The only variable added was the daily hand-holding of the rats as they aged. Is it possible that handling the rats had extended their life span? Indeed, many investigators have been amazed that these rats survived to 904 days of age. The 904 day-old rats in enriched conditions developed a cortex significantly thicker than the cortex of rats living in the standard conditions (Diamond 1988). These experiments offered support to the thesis that the cerebral cortex is capable of responding positively to an enriched environment at any age (See Fig. 1).

Experiments comparing the effects of enrichment on male and female brains are few. Most enrichment studies have been carried out on male brain to avoid the compounding factors associated with the estrous cycle. In one study focused on gender, the female neocortex was found to respond differently from the male neocortex exposed to the same type of enrichment conditions (Diamond 1988). The male showed significant changes in cortical thickness in the occipital cortex, but no significant changes in the somatosensory cortex. (Although the right cerebral cortex in the brain of the male rat is thicker than the left, especially in the visual or occipital region, an enriched environment appears to alter both the right and left cortex similarly.) In the female, the thickness of the occipital cortex increased significantly in response to enrichment, although not as much as in the male, but the thickness of the somatosensory cortex increased significantly more in the female than in the male. In a follow-up experiment, however, in which obstacles were piled up in front of the female food cup to provide a greater challenge to her already enriched environment, the thickness of the occipital cortex increased as much as did that of the male without the additional challenge.

In rats whose testes were removed either at birth or at 30 days of age before the rats were placed in an enriched environment for 30 days, the increases observed in cortical thickness were similar to those of their littermates with intact testes. (Diamond 1988) These findings suggested that testosterone is not implicated in the increases in cortical thickness observed in the brains of rats living in enriched environments. Since sex differences were evident in the responses of the animals to enrichment, interest was 

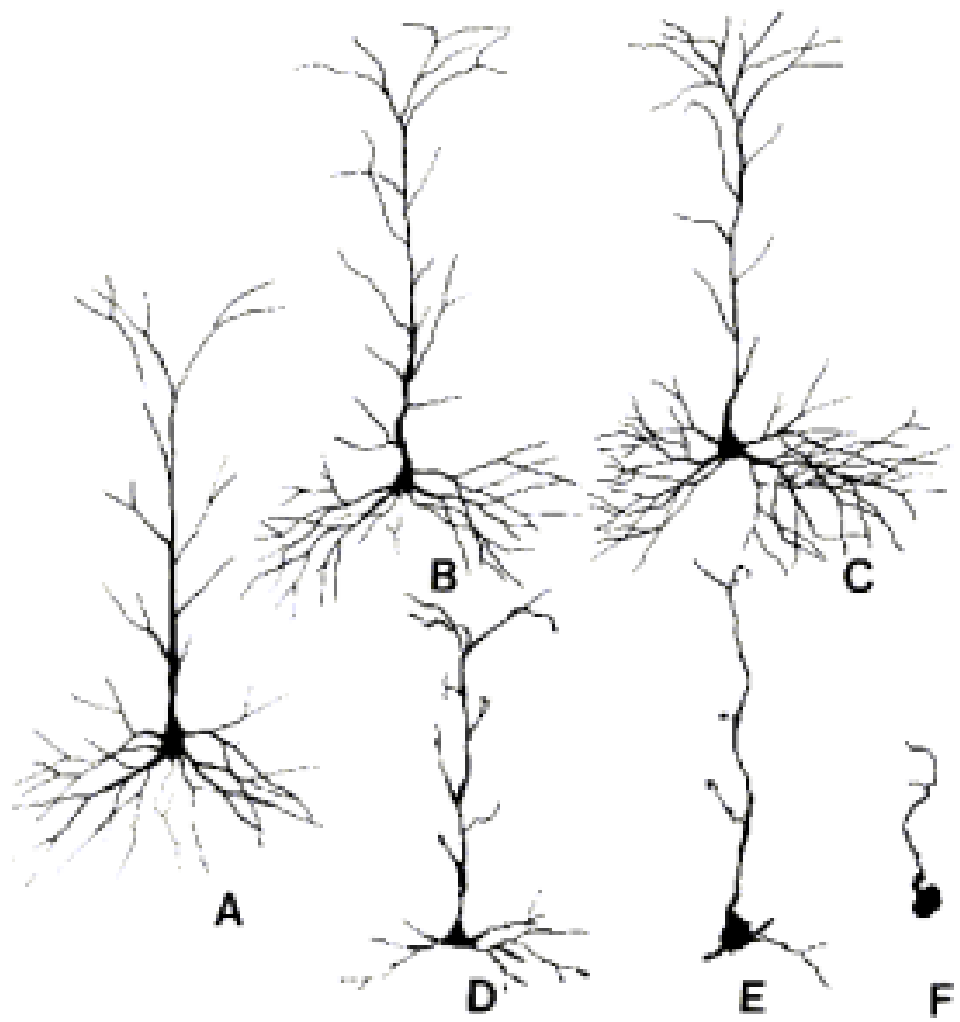

Fig. 1 - Two possible patterns of age-related alterations in cortical pyramidal cells. The normal mature neuron (A) may show regressive dendritic changes characterized by loss of basilar dendritic branches and eventual loss of the entire dendritic tree $(\mathrm{D}, \mathrm{E}, \mathrm{F})$. Other neurons $(\mathrm{B}, \mathrm{C})$ may show progressive increase in dendritic branching. Drawing based on Golgi impregnations.

now focused on the brains of pregnant rats, in which the concentrations of sex steroid hormonal concentrations are greatly altered. The brains of female rats living in the enriched environment from 60 to 90 days and then becoming pregnant and returning to enrichment until 116 days of age were compared between nonpregnant and pregnant animals living in an impoverished environment for the same time periods. When animals from the two groups were autopsied at 116 days, no significant differences in cortical thickness were found. Evidently, pregnancy has an effect on the cerebral cortex regardless of whether the environment is impoverished or enriched.

These initial experiments, all of which were replicated, clearly indicate gender differences in the brain's response to enrichment. Having dealt with the independent variables, we turn to the impact of dependent variables in the enrichment paradigm. For these studies, one must look at: duration of exposure, brain anatomy and chemistry, presence of lesions or fetal neocortical grafts, negative air ions, stress, physical activity and nutrition, as well as behavioral effects. These are discussed in turn below.

Duration: The duration of exposure to the enriched environment is clearly a significant dependent variable that must be factored into research in this area. As short a period as 40 minutes of enrichment has 
been found to produce significant changes in RNA and in the wet weight of cerebral cortical tissue sampled. One day of enrichment was insufficient to produce measurable changes in cortical thickness, whereas four consecutive days of exposure (from 60 to 64 days of age) to an enriched environment did produce significant increases in cortical thickness, but only in the visual association cortex (area 18) (Diamond 1988).

When young adult rats were exposed to 30 days of enrichment, however, the entire dorsal cortex, including frontal, parietal and occipital cortices, increased in thickness. Extending the duration of the stay in enriched conditions to 80 days did not produce any greater increase in cortical thickness than that seen at 30 days (in fact, it was often even less); however, the longer the rat remained in the enriched conditions, the longer the cortex retained its increased dimensions following return to the standard environment (Bennett et al. 1974). When we looked at age-related differences in the context of duration of stay in the enriched environment, we found that old rats ( 766 days of age) placed in enriched conditions for 138 days showed an increase in cortical thickness that was quite similar to that observed in young adult rats (60 days of age) that had lived in enriched conditions for 30 days.

Anatomical and chemical components: Early experiments, and those to follow in subsequent years, again demonstrated significant differences in brain chemistry and anatomy associated with enriched living conditions. Anatomical increases include all of the structural constituents measured in the cerebral cortex to date, such as cortical thickness (Diamond et al. 1964), nerve cell soma size, nerve cell nuclear size (Diamond 1988), dendritic dimensions (Holloway 1966, Greenough et al. 1973), dendritic spines, synaptic size and number (Mollgaard et al. 1971, Black et al. 1990), number of glia, capillary diameter (Diamond 1988), dendritic number after lesions (McKenzie et al. 1990), and successful tissue grafts, (Mattsson et al. 1997). Chemi- cal increases include: total protein, RNA-to-DNA ratio, cholinesterase-to-acetylcholine ratio, Nerve Growth Factor mRNA, cyclic AMP, choline acetyltransferase, cortical polyamines, NMDA (N Methyl D Aspartate) receptors, and hexokinase, etc.

Lesions: Another variable has to do with the impact of enriched conditions on purposefully incurred brain lesions. In a 1990 study, 60-day-old rodents were exposed for 30 days to either an enriched or standard environment two days after having received a lesion in the left frontal cortex that created a motor dysfunction in the right forepaw. Animals living in the enriched condition showed significant increases in cortical dendritic branching in both hemispheres, the lesioned and the non-lesioned sides, along with a significant return of motor function in the right forepaw compared to those animals living in standard conditions (McKenzie et al. 1990).

Fetal neocortical graft: Similarly, providing an enriched environment to rats that had undergone fetal neocortical grafts one week after lesioning was found to improve behaviorally and to reduce the atrophy in the thalamus, a major structure beneath the cortex that supplies neural input to the cortex (Mattsson et al. 1997). The fact that the fetal neocortical graft when placed in the lesioned cerebral cortex could prevent atrophy in the underlying thalamus as a consequence of enrichment is of great interest to researchers considering the future possibility of using such grafts for brain-damaged individuals.

Air ions: The possibility that physical environmental stimuli other than those classically regarded as "sensory" could have an effect on the brain was tested experimentally by exposing rats living in enriched or standard environments to high concentrations of negative air ions. The experiments were undertaken to determine whether the effect of negative ions on serotonin, the putative second messenger cyclic-AMP, and on cyclic GMP in the cerebral cortex, differ depending on whether the animals lived in enriched or standard conditions. Studies demonstrated that rats placed in the enriched environment 
in the presence of enhanced negative air ions (ion density of $1 \times 10^{5}$ ) showed a significant decrease in serotonin, an effect not found in the brains of animals living in standard conditions (Diamond et al. 1980). Measurements of cyclic AMP decreased as well in the brains of the animals living in the enriched conditions, but cyclic GMP did not. These results indicate the importance of considering air quality and atmospheric conditions in determining the brain's response to enrichment.

Stress: The presence or absence of stress represents yet another variable to be taken into consideration in such studies, certainly so in any extrapolation of these findings to humans. Stress is a major factor in contemporary, fast-moving urban life. Crowding, for example, is deemed stressful under conditions where competition for space or food is likely. Experiments were set up to assess the effect of crowding on the brains of rats maintained in an enriched environment. To create a condition in which crowding would be experienced as stressful, 36 rats were placed in an enrichment cage usually housing only 12 rats, and kept there for 30 days. The results indicated that, compared with rats living in standard conditions, the thickness of the medial occipital cortex increased significantly whether the enrichment cage housed 12 or 36 animals, (Diamond et al. 1987). One hypothesis to come from this study was that the animals' interaction with the toys might be diverting their attention or entertaining them sufficiently to mitigate the stress of the crowded condition.

Chronic stress has been reported by Meaney et al. (1988) to produce excess glucocorticoids, which are toxic to neurons - especially those of the hippocampus. Aged rats are particularly vulnerable to chronic stress. The investigations of Meaney showed that enriching the living conditions of old rats, or handling them in their infancy, helps to prevent stress-related hippocampal damage.

It is possible that stress can be produced by increasing the frequency with which the various objects in the enrichment cage are changed. In all pre- vious studies, objects had been replaced daily or at least several times each week. Then the question was asked whether increasing the frequency of changing the objects would further increase the growth of the cortical thickness, or, alternatively, would it be experienced as a stress factor, given that the animals were inhibited from interacting with them in the more leisurely manner to which they were accustomed. For these experiments, rats 60 to 90 days of age found their objects changed every hour for three hours on four nights of each week for four consecutive weeks. Under this regime, the cerebral cortical thickness did not grow significantly compared to cortices from rats whose objects were changed several times each week for four weeks (Diamond, unpublished.)

Corticosteroids, released under stress, have been shown to reduce cortical thickness and future experiments would be necessary to compare differences in corticosteroid levels in animals exposed to these differing conditions.

Behavior: Psychologists have known for a long time that early experience influences the adult performance of an animal. In experiments in the 1950s (Bingham and Griffiths 1952 and Forgays and Forgays 1952) investigators were interested in determining how much experience in complex environments was necessary to produce a highly intelligent adult animal and when, specifically, during early life these experiences had to occur. These studies showed that all of the animals maintained in enriched conditions were better problem solvers than those with no enrichment; however, in some other occasions, using other tests, enriched rats did not perform significantly better than controls.

One of the most robust effects of environmental enrichment on the behavior of rats appears in the areas of learning and memory. Investigators (York et al. 1989 and Kempermann et al 1997) studying the effects of enrichment in the rat brain have reported that new nerve cells develop in the adult dentate gyrus, an area dealing with recent memory 
processing. In the York experiments the rats were 60 to 90 days of age (truly adult animals) during the enrichment experience, whereas in the Kempermann experiments the mice were 21 to 40 days of age. These finding are significant because neurogenesis had not previously been found in the cerebral cortex of the mammalian adult. Earlier studies had found that enriched environments stimulate the growth of dendrites in the dentate gyrus, and only in female rats. (Juraska et al. 1985).

Physical Activity: One component of enrichment is the physical exercise involved in the animals' having to move about the cage, interacting with and climbing upon the novel objects. These activities appear to influence the motor cortex as well as the hippocampus. Olsson et al. (1994) showed that rats living in enriched environments at 50 days of age showed higher expression of the gene-encoding glucocorticoid receptors and induction of genes for Nerve Growth Factors in the hippocampus.

Nutrition: Nutrition is clearly an important variable to consider in all studies dealing with brain and behavior. Environmental enrichment and impoverishment have pronounced effects on nutritionally deficient animals. One study compared the effects of environmental enrichment on the offspring of mother rats living on protein-rich or protein-deficient diets during pregnancy (Carughi et al. 1990). The protein-rich diet proved beneficial for the healthy development of the cerebral cortical dendrites in young rats and even more so when combined with an enriched environment.

The cerebral cortical dendrites in rat pups from mothers with a protein-deficient diet were significantly less well developed than those of their counterparts, but, of greater importance, the cortex from the protein-deficient animals did not significantly increase with enrichment. On the other hand, when protein-deficient pups were fed a protein-rich diet and maintained in an enriched environment during their early postnatal life, cortical development improved almost to the level seen in rat pups from mothers on a high-protein diet during pregnancy followed by postnatal enrichment. These data are very encouraging, because they suggest the possibility of making up for lost brain growth during pregnancy by enriching both the diet and the environmental conditions during the postnatal period.

Another dietary factor significant to optimal brain function is glucose. The brain depends almost exclusively on glucose for its energy. Synapses use a great deal of energy and glucose supplies this energy. Although we know that different parts of the brain use glucose at different rates, to learn which of 30 discrete brain regions were most active in adult rats placed in enriched living conditions from 57 to 87 days of age, we studied their radioactive glucose uptake during this 30-day period and compared it with that of rats raised in standard conditions (Diamond 1988). Again, the cerebral cortex showed the greatest differences between enriched and nonenriched groups, but, surprisingly, of the two groups, glucose uptake was lower in rats maintained in enriched conditions. We concluded from this finding that glucose uptake is more efficient in the brain of animals living in enriched environments. Out of the 30 areas of the brain measured, including the cortex, only one area showed significantly greater glucose uptake in the enriched animals: the corpus callosum, specifically, the large mass of axons connecting the nerve cells between the two cerebral hemispheres. Could the axons forming the corpus callosum from the nerve cells in the cerebral cortex be more active than the nerve cell bodies from which they arise? Yet the right and left cerebral cortices show comparable cortical thickness increases with enrichment due to the effects on dendritic branching, but now the data show that the rates of glucose utilization in both the frontal and parietal cortices were $13 \%$ lower in the enriched rats than in the standard control rats, a paradox to be untangled in the future.

Methodological issues associated with enrichment research in humans: Of the vast number of animal studies that yield results of interest to human 
research, studies on the impact of an enriched environment on brain development and behavior can be of enormous interest to humans. Despite similarities in some key respects between the brain of the rat and other mammals, replicating or extrapolating from anatomical and chemical studies conducted in animals is fraught with difficulty, for obvious reasons. Not only is it not presently possible to control all of the experimental variables at work in humans, but the diversity and complexity of human experience militates against designing experiences comparable to those used with lower animals.

Nevertheless, these studies and what few human studies have been done, suggest that there are measurable benefits to enriching an individual's environment in whatever terms that individual perceives his immediate environment as enriched. At the very least, this work indicates that there are many opportunities for enhancing brain activity and behavior at all ages, and that they can have pronounced effects throughout the life span.

\section{RESUMO}

Antes de 1960, os cientistas consideravam o encéfalo como imutável, sujeito apenas ao controle genético. Entretanto, no início dos anos 60, alguns pesquisadores especulavam seriamente que influências ambientais podiam ser capazes de alterar a estrutura cerebral. Por volta de 1964, dois laboratórios de pesquisa demonstraram que a morfologia e a química ou a fisiologia do cérebro poderia ser modificada pela experiência (Bennett et al. 1964, Hubel e Wiesel 1965). Desde então, a capacidade do cérebro a responder para responder a insumos ambientais, especificamente ao "enriquecimento", tornou-se um fato aceito por neurocientistas, educadores e outros. De fato, a demonstração de que o enriquecimento ambiente pode modificar componentes estruturais do cérebro de rato, em qualquer idade, alterou suposições prevalentes a respeito da plasticidade cerebral (Diamond et al. 1964, Diamond 1988).

O córtex cerebral, a área associada com o processamento cognitivo superior, é mais receptivo do que outras partes do encéfalo ao enriquecimento ambiental. A mensagem é clara: embora o encéfalo possua uma organização macro- estrutural relativamente constante, o sempre-mutável córtex cerebral, com sua microarquitetura complexa de potencial desconhecido, é fortemente moldado pelas experiências antes do nascimento, durante a juventude e, em verdade, ao longo de toda a vida. É essencial que se note que os efeitos do enriquecimento sobre o encéfalo têm consequências no comportamento. Pais, educadores, geradores de políticas e quaisquer indivíduos podem todos se beneficiar de tal conhecimento.

Palavras-chave: enriquecimento, córtex cerebral, hipocampo, envelhecimento, neurogênese em adultos, dendritos.

\section{REFERENCES}

Bennett EL, Diamond MC, Krech D and RosenZWEIG MR. 1964. Chemical and anatomical plasticity of the brain. Science 164: 610-619.

Bennett EL, Rosenzweig MR and Diamond MC. 1974. Effects of successive environments on brain measures. Physiol and Behavior 12: 621-631.

Bingham WE AND GRIFfiths WJ. 1952. The effect of different environments during infancy on adult behavior in the rat. J Comp Physiol Psychol 45: 307312 .

Black JE, Isaacs KR, Anderson BJ, Alcantara AA AND GREeNOUGH WT. 1990. Learning causes synptogenesis, whereas motor activity causes angiogenesis, in cerebellar cortex of adult rats. Proc Nat Acad Sci (USA) 87: 5568- 5572.

Carughi A, Carpenter KJ and Diamond MC. 1990. The developing cerebral cortex: nutritional and environmental influences. Malnutrition and the infant brain. Wiley-Liss p.127-139.

Darwin C. 1874. The descent of man. Rand McNally, Chicago ed 2.

Diamond MC. 1988. Enriching heredity. The Free Press, New York.

Diamond MC, Krech D and Rosenzweig MR. 1964. The effects of an enriched environment on the rat cerebral cortex. J Comp Neurol 123: 111-119.

Diamond MC, Connor JR, Orenberg EK, Bissell M, 
Yost M And Krueger A. 1980. Environmental influences on serotonin and cyclic nucleotides in rat cerebral cortex. Science 210: 652-654.

\section{Diamond MC, Greer ER, York A, Lewis D, Barton T} AND LIN J. 1987. Rat cortical morphology following crowded-enriched living conditions. Exp Neurol 96: 241-247.

Forgays G AND Forgays J. 1952. The nature of the effect of free environmental experience in the rat. $\mathrm{J}$ Comp Physiol Psychol 45: 322-328.

Greenough WT, Volkman R and Juraska JM. 1973. Effects of rearing complexity on dendritic branching in fronto-lateral and temporal cortex of the rat. Exp Neurol 41: 371-378.

Holloway RL. 1966. Dendritic branching: some preliminary results of training and complexity in rat visual cortex. Brain Res 2: 393-396.

Hubel DH ANd Wiesel TN. 1965. Binocular interaction in striate cortex of kittens reared with artificial squint. J Neurophysiol 28: 1041-1059.

Jacobs B, Schall M and Scheibel AB. 1993. A quantitative dendritic analysis of Wernicke's area in human. II. Gender, hemispheric, and environmental changes. J Comp Neurol 327: 97-111.

Juraska JM, Fitsch JM, Henderson C and Rivers N. 1985. Sex differences in the dendritic branching of dentate granule cells following differential experience. Brain Res 333: 73-80.

Kempermann G, Kuhn HG and Gage FH. 1997. More hippocampal neurons in adult mice living in an enriched environment. Nature 386: 493-495.

Krech D, Rosenzweig MR and Bennett EL. 1960. Effects of environmental complexity and training on brain chemistry. J Comp Physiol Psychol 53: 509519 .

Mattsson B, Sorensen JC, Zimmer J and Johansson BB. 1997. Neural grafting to experimental neocortical infarcts improves behavioral outcome and reduces thalamic atrophy in rats housed in enriched but not standard environments. Stroke 2: 1225-1231.
McKenzie A, Diamond MC, Greer ER, Woo L And Telles T. 1990. The effects of enriched environment on neural recovery following lesioning of the forelimb area of rat cortex. Am Physical Therapy Annual Conf, Anaheim, CA.

Meaney MJ, Aitkin DH, Bhatnagar S, Van Berkel C ANd SAPOLSKy RM. 1988. Postnatal handling attenuates neuroendocrine, anatomical and cognitive impairments related to the aged hippocampus. Science 283: 766-768.

Mollgaard K, Diamond MC, Bennett El, RosenZWEIG MR AND LindNER B. 1971. Quantitative synaptic changes with differential experience in rat brain. Int J Neurosci 2: 113-128.

Olsson T, Mohammed AH, Donaldson LF, HenriksSON BG AND SECKL JR. 1994. Glucocorticoid receptor and NGFI-A gene expression are induced in the hippocampus after environmental enrichment in adult rats. Mol Brain Res 23: 349-353.

Rampon C, Jiang CH, Dong H, Tang Y-P, Lockhart DJ, Schultz PG, Tsien JZ ANd Hu Y. 2000. Effects of environmental enrichment on gene expression in the brain. Proc Nat Acad Sci (USA) 97: 1288012884 .

Rosenzweig MR and Bennett EL. 1996. Psychobiology of plasticity: Effects of training and experience on brain and behavior. Behav Brain Res 78: 57-65.

Spurzheim JC. 1815. The physiognomical system of Drs Gall and Spurzheim. Baldwin Cradock and Joy, $2^{\text {nd }}$ ed., London: 554-555.

York AD, Breedlove SM and Diamond MC. 1989. Housing adult male rats in enriched conditions increases neurogenesis in the dentate gyrus. Soc Neurosci Abstracts 15: 962 (\#383.11). 